\title{
The complexities of decentralization in a globalizing world
}

\section{Journal Article}

Author(s):

Engel, Stefanie; Palmer, Charles

Publication date:

2011-10

Permanent link:

https://doi.org/10.3929/ethz-b-000029276

Rights / license:

In Copyright - Non-Commercial Use Permitted

Originally published in:

Environmental and Resource Economics 50(2), https://doi.org/10.1007/s10640-011-9466-x 


\title{
Complexities of Decentralization in a Globalizing World
}

\author{
Stefanie Engel · Charles Palmer
}

Accepted: 16 March 2011 / Published online: 2 April 2011

(C) Springer Science+Business Media B.V. 2011

\begin{abstract}
In many developing countries, decentralization programmes for natural resource management aim to induce incentives for sustainable resource management at the local level. The effectiveness of such programmes has, however, suffered from weak property rights to the resource and by the presence of externalities. Growing economic integration among countries has exacerbated these problems by increasing the exposure of local user groups to commercial actors interested in resource extraction. In this paper, the interplay of decentralization and globalization in affecting environmental outcomes and community welfare is analysed through a game-theoretic model of community-firm interactions. The results highlight the complexities of policy design. First, by raising the extractive value of the resource, globalization may lead to communities negotiating resource extraction agreements with firms. Second, with a lack of effective state enforcement of community resource rights, communities may be unable to assume de facto ownership over the resource, while commercial actors succeed in exploiting resources without community consent. No single policy option provides a panacea to counteracting these negative effects. Instead, a mix of policies, combining incentive payments along with the provision of more secure property rights and poverty alleviation is shown to have the potential to improve both environmental outcomes and community welfare.
\end{abstract}

Keywords Bargaining - Decentralization - Globalization · Natural resources · Poverty · Property rights $\cdot$ Self-enforcement

\footnotetext{
S. Engel ( $\varangle)$

Institute for Environmental Decisions, ETH Zürich, Universitaetstrasse 22, CHN K 76.3, 8092 Zurich, Switzerland

e-mail: stefanie.engel@env.ethz.ch

C. Palmer

Department of Geography and Environment, London School of Economics (LSE),

Houghton Street, London WC2A 2AE, UK

e-mail: c.palmer1@1se.ac.uk
} 


\section{Introduction}

Over the previous two decades, important institutional changes have occurred worldwide that have profoundly affected the links between poverty and natural resource management. Two trends stand out in particular. First, decentralization reforms have led to a full or partial transfer of property rights and responsibilities over natural resources from the central state to the local level in many countries around the world (Ribot 2002). This trend, also referred to as 'devolution', has led to a more prominent role for local resource-dependent and poor communities in natural resource management. The second trend stems from globalization. Growing economic integration among countries has affected the economic incentives faced by local communities and has increased the role of the private sector in resource extraction (Johnson et al. 2001; World Resources Institute (WRI) 2005). ${ }^{1}$ So while decentralization is shifting decision-making processes to a more local level, globalization is increasing the role of global actors in the process.

Devolution intends to improve resource management outcomes by creating a sense of ownership over resources by those who use them ${ }^{2}$ (see for example, Ostrom 1990; Edmonds 2002). Poverty alleviation is often a side objective of devolution because local communities could benefit from more sustainable management outcomes and also may be able to capitalize on their newly established resource rights. A number of studies, however, highlight weaknesses underlying current decentralization programs (e.g. Baland and Platteau 1996; Larson and Ribot 2004; Bulte and Engel 2006; Ribot et al. 2006). In particular, insufficient transfers of resource management responsibilities, insecure property rights, and a failure in dealing with externalities have often undermined the incentives for local communities to manage natural resources sustainably.

A substantial body of research has analyzed the determinants of success of community-based natural resource management (CBNRM) (e.g., Ostrom 1990; Bromley 1992; Baland and Platteau 1996; Agrawal 2001). This literature, however, focuses largely on intracommunity processes. ${ }^{3}$ Yet, globalization has raised the commercial pressure on natural resources in resource-rich areas of the developing world (Engel and López 2008). This raises the value of intensive resource extraction vis-á-vis less environmentally damaging uses and, as we show in this paper, reinforces problems of insecure community property rights. Globalization implies that communities can no longer be considered in isolation. Rather we need to consider the interaction of local communities with commercial actors, such as firms interested in intensive resource extraction

We analyze the interplay of decentralization and globalization in affecting natural resource management outcomes and poverty. Following, we then proceed to compare a number of alternative policy options that aim to correct for undesirable effects on the environment and on community welfare.

In doing so, we explicitly focus on the interactions between local communities and commercial actors (firms). Such interactions may lead to one of three possible outcomes

\footnotetext{
1 Despite growing 'resource nationalisation' and increased state control over resources such as oil and gas, for example, in Russia and Venezuela, since the turn of the century, the overall long-term trend has been one of growing economic integration among countries.

2 It should also be noted that pragmatic reasons such as a history of state failure to manage resources sustainably and government budget cuts have also driven trends towards decentralization in natural resource management in many developing nations (Bulte and Engel 2006).

3 Those studies that do examine community interactions with the external environment tend to be case studies that focus on generalized factors such as ones related to, for example, demography and technology and not specific external actors per se. For recent reviews see Agrawal (2007) and Larson and Soto (2008).
} 
(Engel et al. 2006; Engel and López 2008). First, given weak property rights, commercial actors may unilaterally exploit resources without resource owners' consent. This outcome was, for example, observed in a case of a petroleum firm exploiting community land in Ecuador despite the community's resistance. ${ }^{4}$ Second, the two parties may negotiate a resource exploitation agreement, under which the commercial actor compensates resource owners for the exploitation of the resource. This case is, for example, the most frequent outcome in Indonesia, where communities have exercised newly gained property rights over forest resources by negotiating logging agreements with timber companies (Palmer 2006). ${ }^{5}$ Third, communities may successfully fend off commercial interests and prevent exploitation of the resource, as observed in a conflict between an indigenous community and a mining firm in Brazil. ${ }^{6}$ In the first two cases, the outcome is often one of pervasive environmental damages, with local resource owners receiving little or no financial compensation.

In this paper, we adapt a model from earlier work by Engel et al. (2006), and Engel and López (2008). The model combines conflict and bargaining theory and sheds light on the conditions under which such community-firm interactions result in conflict vs. negotiated agreements as well as the impacts on community welfare and the environment. It differs from earlier analyses as follows.

The previous analyses focus on the impact of endogenous third-party interventions that are linked to the level of resource extraction negotiated. Such interventions cause the resourceextraction level and negotiated payment to be non-separable. Here we simplify the model by abstracting from such third-party interventions. In our model, the extraction level and negotiated payment distribution are hence separable. This simplifies the analysis considerably and allows us to present a more intuitive analysis of decentralized community-firm interactions and the impacts of globalization on these interactions. The simplified model also permits us to better assess and compare the effectiveness of four alternative policy approaches for enhancing environmental quality and/or community welfare: (i) external property rights enforcement; (ii) poverty alleviation measures; (iii) providing alternative income opportunities to local communities; and, (iv) incentive payments. We show that there are important complementarities between the three approaches. Our analysis of incentive payments draws on an earlier paper by Engel and Palmer (2008). That paper, however, focused only on such payments and did not consider the broader issue of how globalization and different types of policy approaches might affect decentralization outcomes.

The remainder of this paper is structured as follows. Section 2 presents a game-theoretic model on the interactions between resource owners and commercial actors. In Sect. 3 we analyze a number of alternative policy interventions and highlight important interactions between them. Section 4 concludes.

\section{Game-Theoretic Model of Community-Firm Interactions}

To make the presentation more concise, we refer to the commercial actor as 'the firm', to the natural resource owner as 'the community', to the natural resource as 'the resource', and to resource exploitation as 'resource extraction'. In this section we first present a gametheoretic model of community-firm interactions, which links conflict and bargaining theory.

\footnotetext{
4 http://flag.blackened.net/revolt/mexico/reports/taboil.html.

5 See Engel and López (2008) for further examples.

6 Pratap Chatterjee, Gold, Greed \& Genocide in the Americas: California to the Amazon, http://saiic. nativeweb.org/ayn/goldgreed.html.
} 
The model consists of two stages. Assuming a context of weak property rights, in the first stage we model de facto property rights over the resource as the result of a war of attrition (conflict) between the community and the firm. In the second stage of the game, the community and firm bargain over a mutually-agreed resource extraction contract. The resulting de facto rights to the resource from the first stage are an important factor in the second stage because they determine the players' reservation utilities, which are a major determinant of bargaining outcomes. In fact, as discussed below, the possibility for successful bargaining arises only in the case where the community can establish de facto rights to the resource. In what follows, the conflict component is discussed first, followed by bargaining over resource extraction. We then link the two components and discuss the impact of parameter values on extraction and community welfare. This section ends with a discussion of the impacts of globalization within the context of our model.

\subsection{Conflict Theory and Property Rights Formation}

To allow for the common weaknesses of devolution programs as described in the introduction, the community's property rights are assumed to be weakly defined in a legal sense and poorly enforced by the government. Communities then have to rely on self-enforcement to stop firm operations. In practice, this often takes the form of blockades or sabotaging equipment required for resource extraction. ${ }^{7}$ With weak de jure property rights, each of the actors can in principle obtain de facto property rights over the resource, e.g. the firm may unilaterally exploit the resource if it has enough power to win a war of attrition, or the community may prevent that if the power conditions are reversed. The implications of more secure, government-enforced community property rights are discussed in Sect. 3.

De facto property rights are modeled as the outcome of a war of attrition between a commercial actor and a resource owner. Resource extraction is assumed to require a specific factor (capital) that is available to the firm, but not to the community. ${ }^{8}$

Each period the community is able to stop firm operations it obtains use and nonuse values from the unexploited resource, denoted by $b$. For example, in the case of forest, the community could use it for the collection of fuelwood and non-timber forest products, hunting, and other uses; it may also consider ecological services from the standing forest (e.g., erosion prevention, water retention) as well as non-use values (e.g., the cultural value of living near a forest). Note, however, that due to externality problems, $b$ is unlikely to reflect the full social value of the forest.

If, by contrast, the firm wins the conflict, the firm receives one-time profits $v$ from unilateral resource extraction. Contrary to Engel et al. (2006) and Engel and López (2008), we also allow for the possibility that the community receives a positive, minimum payment from the firm even in the case of unilateral exploitation by the firm. Such a payment has been observed, for example, in Indonesia (see Palmer 2006). Let this minimum payment be denoted by $\Pi_{\min }^{C}>0$. Thus, if the firm wins the conflict it receives $v-\Pi_{\min }^{C}$. The discount rates of the community and the firm are, respectively, denoted by $r^{C}$ and $r^{F}$. Furthermore,

\footnotetext{
7 Hook and Ganguly (2000) study three cases of increased conflict in countries where multinational firms undertake resource extraction activities and where local communities have attempted to blockade or sabotage these activities: Shell in the Niger Delta, Bougainville Cooper in Papua New Guinea, and Freeport McMoran in Indonesia. Richani (2005) examines how the presence of commercial actors, especially those in the extraction industries, contributed to intensified land conflicts in Colombia.

8 This assumption can be justified on the basis that communities are poor (have low savings) and have a disadvantage in the credit market vis-à-vis the firm, associated with capital market imperfections (see for example, Bose 1998).
} 


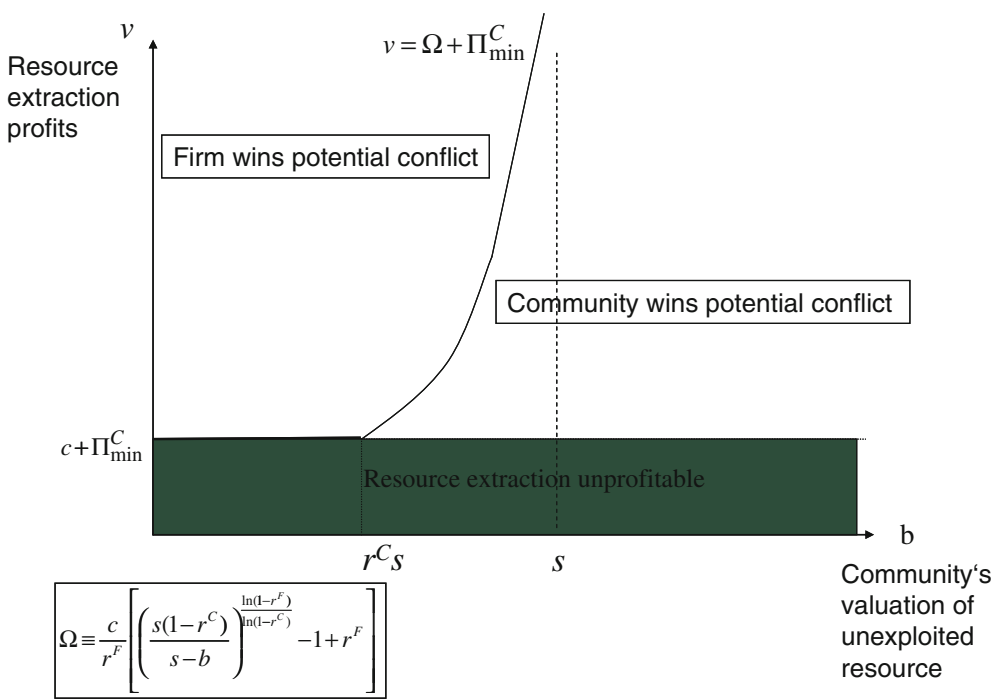

Fig. 1 Outcomes of the conflict game

$c$ denotes the firm's fixed resource extraction costs in each period it attempts to extract unilaterally. The community can stop such unilateral resource extraction by setting up a blockade, in which case it incurs a cost of $s$ per period of blockading.

In general, the war of attrition is won by the party that is able to stay in a potential conflict longer. The results of the conflict game are presented in Fig. 1 and shown formally in Engel et al. (2006). Given that the game is played in a context of perfect information, the intuition behind these results is as follows. First, consider the case where $s>b / r^{C}$. Thus, the cost of setting up a blockade for even just one period $(s)$ already exceeds the present value of benefits obtained from the unexploited resource forever $\left(\int_{t=0}^{\infty} b e^{-r t} d t=\frac{b}{r^{C}}\right)$. In this case, the community will never fight and the firm will simply go ahead and extract as long as net profits from doing so are positive. This is the case if profits exceed the corresponding costs, which are composed of logging costs (c) and minimum payment to the community $\left(\Pi_{\text {min }}^{C}\right)$. The intersect of the boundary condition for the conflict game in Fig. 1 is thus given by the line $\left(v=c+\Pi_{\min }^{C}\right)$. Now consider the case where $s<b$. The benefits from protecting the resource for just one period $(b)$ already outweigh the costs of blockading in that period. Thus, the community will always fight, and the firm, knowing this, will withdraw. For intermediate values of $b\left(s r^{C}<b<s\right)$, the boundary condition, represented by the line

$$
v=\Omega+\Pi_{\min }^{C}, \quad \text { where } \Omega \equiv \frac{c}{r^{F}}\left[\left(\frac{s\left(1-r^{C}\right)}{s-b}\right)^{\frac{\ln \left(1-r^{F}\right)}{\ln \left(1-r^{C}\right)}}-1+r^{F}\right]
$$

in Fig. 1, is derived by computing for each player the maximum time that he can stay in conflict and still receive a non-negative payoff, and by then equating these maximum times (please see "Appendix" for formal derivation).

If $v>\Omega+\Pi_{\min }^{C}$, the firm is able to stay in conflict longer than the community and thus wins the conflict. In this case the firm effectively has access to both the resource and capital and is able to exploit the resource unilaterally with only the minimum payment made to the 
community. The community effectively loses its property rights over the resource and its payoff is given by $\Pi_{\min }^{C}$. If, $v<\Omega+\Pi_{\min }^{C}$, then the community is able to stay in conflict longer than the firm, and is thus able to self-enforce its property rights over the resource. In the absence of bargaining, community payoffs are given by the present value of the flow of benefits from the unexploited resource to the community, $\frac{b}{r^{C}}$.

As argued in Engel et al. (2006), inspection of the boundary condition indicates that the community is more likely to self-enforce its property rights over the resource $\left(v<\Omega+\Pi_{\min }^{C}\right)$ when the community's discount rate $\left(r^{C}\right)$ is lower and when the community's valuation of the unexploited resource $(b)$ is higher. These results are intuitive. An increase in $b$ raises the community's benefits from fighting, which allows it to stay in conflict longer thereby raising the likelihood that it is able to win the conflict. Similarly, a higher discount rate induces the community to value the immediate fighting costs more than the long-run benefits from winning. This reduces the maximum length of time the community would stay in conflict and thus its chances of winning.

\subsection{Community-Firm Contracting Over Resource Extraction}

We assume Rubinstein-type bargaining where a community and a firm make alternating offers to define a mutually-agreed resource extraction contract. ${ }^{9}$ For an interior solution, the negotiation outcome can be presented in the form of an asymmetric Nash Bargaining Solution (NBS) (Muthoo 1999). Thus, the negotiated payments to the community $\left(\Pi^{C}\right)$ and firm $\left(\Pi^{F}\right)$ are obtained by solving the following Nash bargaining problem ${ }^{10}$

$$
\begin{aligned}
& \max _{\Pi^{C}, \Pi^{F}}\left[\Pi^{C}-d^{C}\right]^{\tau}\left[\Pi^{F}-d^{F}\right]^{1-\tau} \quad \text { s.t. } \Pi^{C}+\Pi^{F}=v-c, \\
& \Pi^{C} \geq d^{C}, \quad \Pi^{F} \geq d^{F}
\end{aligned}
$$

where $\tau$ is the community's bargaining power vis-á-vis the firm $(0 \leq \tau<1) . d^{C}$ and $d^{F}$ are the community's and the firm's reservation utilities, respectively, which are given by the results of the conflict component (more below). ${ }^{11} \tau$ is generally increasing (decreasing) in the firm's (community's) discount rate, but may also depend on other factors. The solution to the above Nash bargaining problem yields the following payment to the community

$$
\tilde{\Pi}^{C}=d^{C}+\tau\left(v-c-d^{C}-d^{F}\right)
$$

9 Following Engel et al. (2006), we choose the Nash bargaining solution rather than a non-cooperative-game representation for the following reasons. First, in many real-world settings the local government often takes on the role of a mediator between firms and communities. An example from Indonesia is presented in Engel et al. (2006). Second, the Nash bargaining solution has been shown to also represent the solution to a noncooperative game of alternating offers where there is some probability that rejection of an offer will lead to a breakdown of the bargaining process (Gintis 2000, Chapter 15).

10 Contrary to Engel et al. (2006), we abstract here from possible differences in resource size between unilateral extraction and a negotiated agreement. The former also explicitly decompose the community's valuation of the unexploited resource into the true value and the proportion of this value considered by the community.

11 Muthoo (1999) distinguishes between players' inside and outside options. Inside options are defined as the payoffs obtained by each player while parties temporarily disagree and negotiations are ongoing (Bulow and Rogoff 1989). Outside options are the parties' payoffs available when bargaining fails permanently (Binmore 1985). While inside and outside options differed in the presence of endogenous third-party interventions modeled by Engel et al. (2006) and Engel and López (2008), they are assumed identical in our simplified version of the model. 
The total 'cake' to be divided in negotiations are the net profits from resource extraction $(v-c)$. The asymmetric Nash bargaining solution implies that each player obtains his reservation utility, and the remaining surplus is divided in proportion to bargaining power. Moreover, if the 'size of the cake' being divided does not exceed the sum of reservation utilities, negotiations fail and the conflict outcome results. That is, negotiations fail if ${ }^{12}$

$$
v-c \leq d^{C}+d^{F} \text {. }
$$

\subsection{Linking Negotiations and Conflict}

We now combine the conflict and bargaining components of our model by linking the reservation utilities to the results of the conflict component. The possibility of bargaining arises from the complementarity between the firm and the community in terms of access to the factors of production required for resource exploitation. The firm has access to capital, while the community may be able to control access to the resource as a consequence of devolution.

If the community is able to establish de facto property rights in a potential conflict with the firm $\left(v<\Omega+\Pi_{\min }^{C}\right)$, its reservation utility is the present value of the unexploited resource $\left(\frac{b}{r^{C}}\right)$, while the firm's reservation utility is its payoffs from using its capital in the next-best activity. Let the latter be denoted by $\bar{d}^{F}$. If the community is not able to establish de facto property rights over the resource, its reservation utility is given by the minimum payment received while the firm receives resource extraction profits net of this payment. Thus ${ }^{13}$ :

$$
\begin{aligned}
d^{C} & =\left\{\begin{array}{ll}
\Pi_{\min }^{C} & \text { if } \mathrm{v} \geq \Pi_{\min }^{C}+\Omega \\
\frac{b}{r^{C}} & \text { if } \mathrm{v}<\Pi_{\min }^{C}+\Omega
\end{array}\right\} \\
\text { and } d^{F} & =\left\{\begin{array}{ll}
v-c-\Pi_{\min }^{C} & \text { if } \mathrm{v} \geq \Pi_{\min }^{C}+\Omega \\
\bar{d}^{F} & \text { if } \mathrm{v}<\Pi_{\min }^{C}+\Omega
\end{array}\right\},
\end{aligned}
$$

Substituting from (4a) and (4b) into (2) and (3) yields the following results. If the firm can establish de facto property rights over the resource $\left(v \geq \Omega+\Pi_{\min }^{C}\right)$, condition (3) always holds with equality. Negotiations do not succeed in this case because the sum of reservation utilities just equals the size of the cake. Thus, both players receive their reservation utilities. This result is intuitive. If the firm is able to establish de facto property rights over the resource, it effectively controls both factors of production. Hence, there is no reason for the firm to share its resource extraction profits beyond the minimum payment.

By contrast, if the community can establish de facto property rights over the resource $\left(v<\Omega+\Pi_{\min }^{C}\right)$, each of the actors has control over one of the factors of production required for resource extraction. Thus, gains from trade are possible as long as extraction profits are large enough to more than compensate both actors for their respective reservation utilities. Substituting from (4a) and (4b) in (2) and (3), community payoffs (and game outcomes) can be written as

\footnotetext{
12 For simplicity, it is assumed that negotiations fail in the case where the size of the cake just equals the sum of reservation utilities. It is easy to see that negotiated payments in this case would just equal reservation utilities, so that negotiation and conflict yield the same results.

13 For simplicity, it is assumed that the firm wins the conflict in the case where $v$ just equals $\Omega+\Pi_{\min }^{C}$.
} 


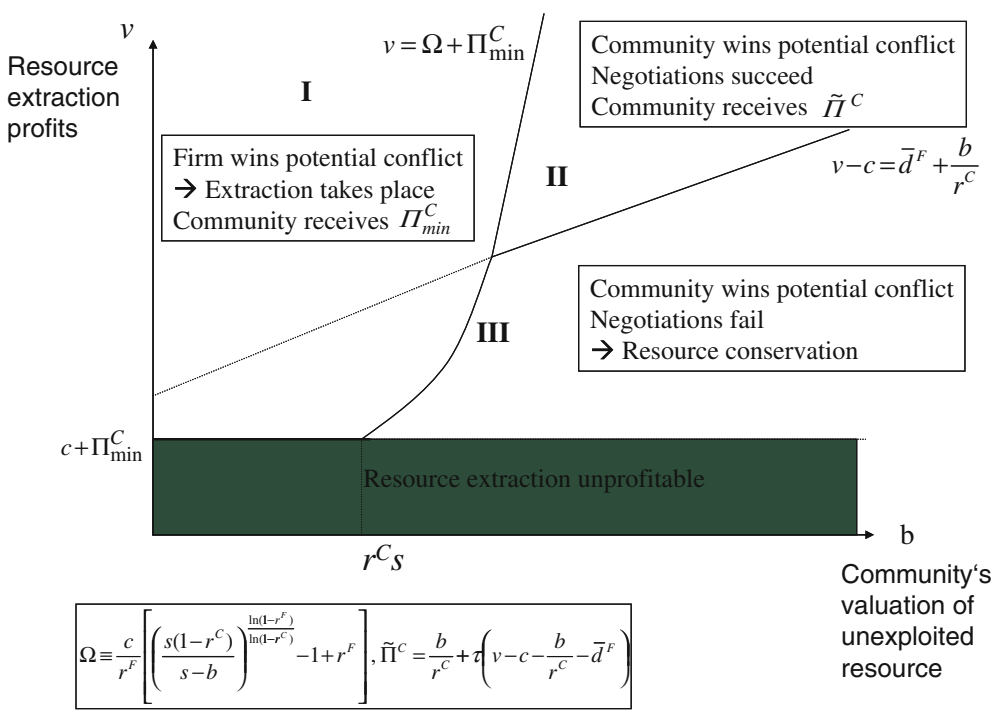

Fig. 2 Outcomes of community-firm interactions

$$
\Pi^{C}=\left\{\begin{array}{l}
\Pi_{\min }^{C} \text { if } v \geq \Pi_{\min }^{C}+\Omega \\
\text { (Firm exploits resource unilaterally; region I in Fig. 2) } \\
\tilde{\Pi}^{C}=\frac{b}{r^{C}}+\tau\left(v-c-\frac{b}{r^{C}}-\bar{d}^{F}\right) \text { if } v<\Pi_{\min }^{C}+\Omega \text { and } v-c>\frac{b}{r^{C}}+\bar{d}^{F} \\
\text { (Negotiated resource extraction agreement; region II in Fig. 2) } \\
\frac{b}{r^{C}} \text { if } v<\Pi_{\min }^{C}+\Omega \text { and } v-c \leq \frac{b}{r^{C}}+\bar{d}^{F} \\
\text { (Community conserves resource; region III in Fig. 2) }
\end{array}\right\}
$$

Figure 2 summarizes these results. Region I represents the outcome where commercial actors unilaterally exploit resources without community consent (represented by the example from Ecuador described earlier), with the community receiving only $\Pi_{\min }^{C}$. Region II represents the case where resource owners and commercial actors agree on a resource exploitation contract (the Indonesian example), with community payoffs equal to $\tilde{\Pi}^{C}$. Region III represents the case where the community fends off commercial actors and opts for resource conservation (the Brazilian example), thus receiving the benefits of resource conservation (the present value of the unexploited resource, $\frac{b}{r^{C}}$ ). In this last case, the present value of the resource exceeds the potential benefits from a resource agreement negotiated with the commercial actor thus resulting in negotiation failure.

Region I and II are both associated with negative environmental outcomes (resource extraction). Specifically, the level of resource extraction in both region I and II is chosen to maximize net profits, $v-c .{ }^{14}$ Community welfare is lowest in region I. Equation (5) also implies that

\footnotetext{
14 In a more sophisticated model one might consider a consideration of local environmental impacts by the community, yielding a lower resource extraction level in a negotiated agreement than in the case where the firm extracts unilaterally. A study of negotiated logging contracts in Indonesia showed, however, that most logging contracts did not contain effective environmental provisions (Palmer and Engel 2007).
} 
the community's payoff from a negotiated agreement $\left(\tilde{\Pi}^{C}\right)$ is increasing in the value of the unexploited resource $(b)$, the profitability of resource extraction $(v-c)$, and the community's bargaining power $(\tau)$; it is decreasing in the community's discount rate $\left(r^{C}\right)$ and independent of blockading costs $(s)$. These results are intuitive: an increase in $b$ and a decrease in $r^{C}$ raises the community's reservation utility $\left(\frac{b}{r^{C}}\right)$, which it has to be at least compensated for in order to agree to any negotiated agreement. An increase in $v-c$ implies an increase in the size of 'the cake' to be divided between community and firm. An increase in community bargaining power allows the community to obtain a greater share of 'the cake'.

\subsection{Impacts of Globalization}

Globalization increases the profitability of commercial resource extraction. Our results summarized in Eq. 5 and Fig. 2 indicate that an increase in $v$ has three effects, two discrete and a continuous one. The first discrete effect is to raise the probability that the firm will succeed in unilateral resource extraction (region I becoming more likely vis-à-vis regions II and III) as such extraction becomes more profitable. This implies that, as long as community property rights to the resource are weakly enforced by the government, globalization may undermine efforts of decentralization. State withdrawal from resource management in the course of decentralization may in this sense fail to achieve the goal of communities developing a sense of ownership over the resource. Moreover, such a shift from region II or III to region I would imply a reduction in community welfare as community payoffs fall to $\Pi_{\mathrm{min}}^{C}$.

Of course, unilateral exploitation by the firm is a somewhat extreme result. If the increase in $v$ from globalization is not strong enough to prevent the community from self-enforcing its property rights over the resource, an outcome in region II or III is still feasible. Our model results imply that the community's payoffs from a resource extraction agreement increase in $v$ (continuous effect within region II). Intuitively, as the size of 'the cake' to be shared increases, the community also receives a higher payoff. As a consequence, the community is also more likely to prefer a resource extraction agreement over the alternative of resource conservation (second discrete effect, making region II more likely vis-à-vis region III). Thus, globalization increases the relative profitability of intensive resource extraction over less environmentally-damaging uses; it thereby induces incentives for communities to cooperate with the firm in the form of resource extraction contracts. This comes at a cost to the environment if a shift from region III to region I or II occurs. ${ }^{15}$

In summary, the model results hence confirm the observation that globalization-by raising the value of intensive resource extraction vis-á-vis that of less environmentally damaging uses-leads to an increased incidence of commercial resource extraction to the detriment of the environment. Moreover, globalization reinforces problems of insecure community property rights and weak state enforcement. Communities only gain in material terms if they succeed in maintaining de facto property rights over the resource through self-enforcement. Otherwise, community welfare decreases as the increased profitability of resource extraction strengthens commercial actors enough to induce a shift into region I.

15 Communities may consider local environmental impacts in their decision-making (i.e., including these in b), but are unlikely to consider environmental impacts at a more regional, national or even global level (e.g., biodiversity and climate impacts). See also previous footnote. 


\section{Policy Options to Counteract Negative Impacts}

We now consider four alternative policy options aiming to correct for undesirable effects on environment and community welfare: (i) external property rights enforcement; (ii) poverty alleviation measures; (iii) provision of alternative income opportunities; and (iv) incentive payments. What are the impacts of these policies on the interplay of decentralization and globalization in resource management? We will see that impacts may be sometimes perverse, and that important complementarities exist among the four policy approaches.

\subsection{External Property Rights Enforcement}

Our analysis in Sect. 2 shows that globalization aggravates the problems of insecure community property rights that have been highlighted in studies of current decentralization processes. How would the provision of more well-defined, secure, and government-enforced property rights for local communities impact on environmental outcomes and community welfare? In our model, this would imply that the issue of self-enforcement ('the conflict game'), represented by the line $v=\Omega+\Pi_{\min }^{C}$ in Fig. 2, would become irrelevant. The firm could no longer succeed in extracting the resource unilaterally without community consent.

The only relevant line in Fig. 2 would be the condition for negotiation breakdown $\left(v-c=\bar{d}^{F}+\frac{b}{r^{C}}\right)$. Communities above and to the left of this line would make resource extraction agreements, while those below and to the right of this line would opt for resource conservation. Environmental outcomes and payoffs will change for those communities previously located in region I, i.e., those that were unable to self-enforce their property rights over the resource. This is illustrated in Fig. 3. Communities in region Ia will use their improved property rights to negotiate resource extraction agreements, thus benefiting from higher payoffs but still to the detriment of the environment. For communities in region Ib, external property rights enforcement will improve both environmental outcomes and community

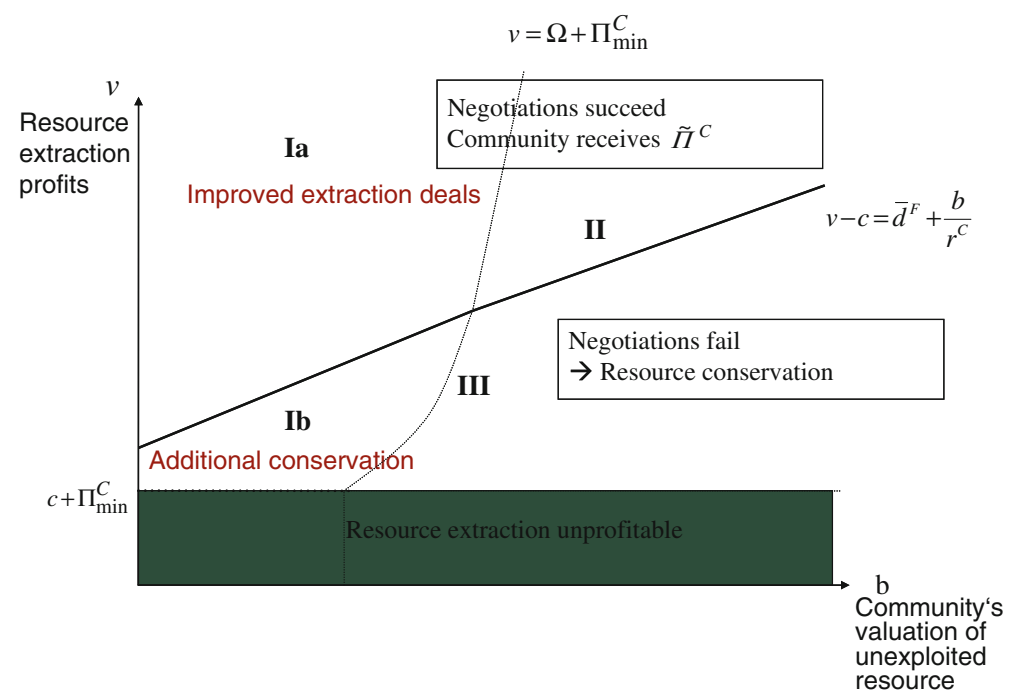

Fig. 3 Impacts of external property rights enforcement 
welfare. These are communities whose valuation of the resource is high enough (or resource extraction profits in the area low enough) to make them prefer conservation over a feasible resource extraction deal.

In summary, external property rights enforcement may not always improve environmental quality as communities may opt to use their improved rights to strike better resource extraction deals; environmental outcomes, however, do not deteriorate, and in some cases may improve. External property rights enforcement also unambiguously improves community welfare for those communities previously unable to self-enforce their property rights. Note that poorer communities (with higher discount rates) are more likely to fall into this group. ${ }^{16}$ Thus, providing more secure property rights would likely help in poverty reduction as it prevents poor communities from being exploited by external, commercial actors.

\subsection{Poverty Alleviation}

Since poorer communities tend to have higher discount rates, we model the impact of a poverty alleviation programme as a decline in $r^{C} .{ }^{17}$ This has two discrete and one continuous effect. First, inspection of the boundary condition in Eq. 1 shows that a reduction in the community's discount rate while holding all else equal would increase $\Omega$, thus shifting the boundary line to the left and increasing the likelihood that $v<\Omega+\Pi_{\min }^{C}$. This would place those communities previously located just to the left of the boundary line in region I, inside region II or III (see Fig. 4). In other words, communities have an increased likelihood of being able to self-enforce their property rights over the resource vis-à-vis the firm, leading to an increase in community welfare.

Second, a decrease in $r^{C}$ raises the community's bargaining power in negotiating agreements with the firm. Thus, poverty alleviation raises the community's payoffs from a resource extraction agreement, $\tilde{\Pi}^{C}$ (continuous effect within region II). Third, a reduction in discount rate increases the net present value of the unexploited resource obtained, hence rotating the boundary condition for negotiation breakdown up and to the left. Communities formerly to the left of this line in region II are therefore more likely to be interested in conservation as a resource management strategy (second discrete effect).

In summary, poverty alleviation, in addition to its direct impacts on community welfare, may also allow communities to strike better resource extraction deals with commercial actors. Therefore, welfare effects are unambiguously positive. Environmental impacts, however, may be unchanged if communities opt for such deals; environmental improvements are achieved only if poverty alleviation induces an increase in the present value of the unexploited resource strong enough so that communities prefer conservation over a resource extraction agreement. Note, moreover, that there may be little improvement for the poorest communities - these are more likely to remain in region I even after the policy and thus have no negotiated payoffs and no ability to enforce conservation.

\footnotetext{
16 Richer communities typically have larger amounts of assets than poorer ones that can be used as collateral when seeking third party financing. Hence, discount rates are expected to be lower because interest rates for refinancing would include a lower-risk premium.

17 Poverty may also affect community valuation of the unexploited resource $(b)$, but the direction of the effect is unclear. While poorer communities may be less resource dependent, they may assign higher values to the local ecological services provided by the resource (e.g., NTFP provision, water quality).
} 


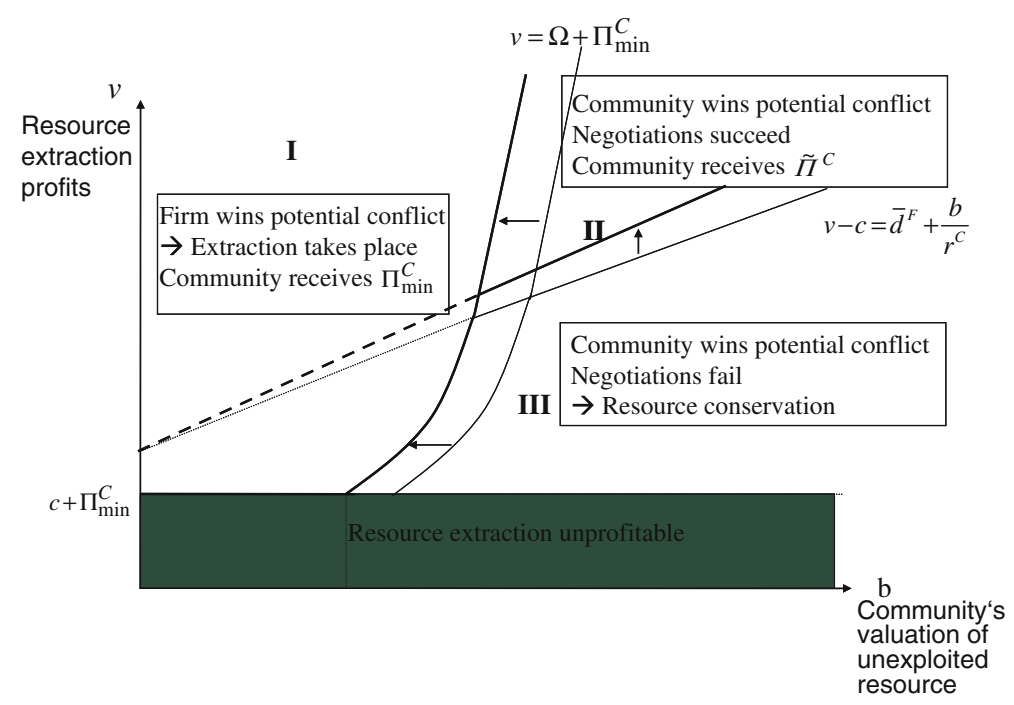

Fig. 4 Impact of poverty alleviation measures

\subsection{Provision of Alternative Income Opportunities}

Another relevant policy intervention is to improve the community's alternative income opportunities outside the resource sector. ${ }^{18}$ This can be modeled in our setting as an increase in the community's opportunity costs of time, and thus blockading costs, $s$. The results summarized in Eq. (5) indicate that this has only one, discrete effect. An increase in $s$ lowers the value of $\Omega$, thereby increasing the likelihood that the firm can establish de facto property rights over the resource and exploit it unilaterally. In Fig. 2, this effect could be reflected as a rightwards shift in the line for the boundary condition of the conflict game $\left(v=\Omega+\Pi_{\text {min }}^{C}\right)$. An outcome in region I becomes more likely vis-à-vis outcomes in region II or III. If a shift to region I occurs, community payoffs fall to $\Pi_{\min }^{C}$. Intuitively, providing improved income opportunities outside resource use reduces the community's ability to collectively enforce property rights over the resource because the opportunity costs of conflict increase. In turn, it is easier for commercial actors to extract the resource unilaterally and keep most of the benefits from doing so. This may well dampen the direct welfare improvement provided by the policy, an unintended side effect not usually considered by policy-makers. Environmental impacts may also be negative if the outcome shifts from region III to region I. In other words, some of the welfare improvement intended by the policy may be dissipated to commercial actors while resource exploitation continues to the detriment of the environment.

\subsection{Incentive Payments}

Incentive payments, such as 'payments for environmental services' (PES), are an increasingly popular mechanism to translate external, non-market values of the environment into real financial incentives for local actors (e.g., Pagiola et al. 2002; Ferraro et al. 2005; Engel

18 Failures in the off-farm labour market have been shown to be an important factor driving deforestation and other inefficient land-use practices in many developing countries (see for example, Bluffstone 1995; Angelsen and Kaimowitz 1999). 
et al. 2008). Incentive payments to potentially eligible communities are made conditional on the adoption of more sustainable land-use practices or conservation measures.

In our model, incentive payments increase the community's per-period valuation of the unexploited resource $(b)$. This can be visualized in Fig. 2 as a horizontal shift to the right from any given starting point while keeping the location of the boundary conditions constant. Our results in Eq. (5) imply that incentive payments have one continuous and two discrete effects. First, an outcome in regions II or III becomes more likely vis-à-vis region I. This happens because by raising the community's benefits from protecting the resource, the payment raises the community's willingness and ability to stay in a potential conflict. Communities are thus more likely to obtain de facto property rights over the resource, implying a gain in community welfare. Second, an outcome in region II becomes less likely vis-à-vis region III, making resource conservation more likely. This is not surprising since the incentive payment is made conditional on conservation.

The continuous effect of an increase in $b$ is less obvious and has important policy implications. As $\tilde{\Pi}^{C}$ is increasing in $b$, the introduction of incentive payments raises community payoffs from a resource extraction agreement. This means that incentive payments, if not designed carefully, would simply lead to better resource extraction deals for communities rather than resource conservation. Intuitively, the mere option of an incentive payment raises the community's reservation utility. The firm, realizing this, will also raise its offer to the community as long as the firm can still retain enough resource extraction profit to be better off than under its next-best activity. Thus, the attempt to use incentive payments to compensate the community for the lost payoffs from resource extraction may be futile. It may not be sufficient to compensate the community for the expected payoff from an extraction agreement that it would have had prior to the implementation of the incentive payment. A higher payment may be necessary to achieve resource conservation, namely one that raises the community's reservation utility to the point where 'the cake' from resource extraction becomes too small to compensate both actors for the loss of their reservation utilities (inducing a shift into region III). ${ }^{19}$

In summary, while the introduction of incentive payments tend to have positive impacts on community welfare, payments need to be designed very carefully to induce a shift from an outcome in region I or II to region III. Otherwise payments would be environmentally ineffective because communities would either use the option of the payment to negotiate better resource extraction deals with commercial actors (region II) or would be unable to enforce resource conservation (region I).

\subsection{Incentive Payments and Poverty-Environment Trade-Offs}

It is often argued that incentive payments could be the 'one stone' to tackle the 'two birds' of environmental sustainability and poverty alleviation (see for example, Landell-Mills and Porras 2002). Our results imply that where decentralization and globalization are leading to community interactions with commercial actors over resource extraction, there may be tradeoffs between the two objectives. If the objective of the payment scheme is to maximize environmental service provision with a given budget, it should target those communities for

19 If incentive payments reflect the true social value of resource conservation, negotiation failure may, of course, be socially efficient. In reality, however, the fact that many environmental services provided by local resources such as forests are public goods (e.g., biodiversity, mitigation of climate change), budgets for incentive payment schemes tend to be limited and are unlikely to represent the full social value of resource conservation. Rather, the issue is often one of maximizing environmental benefits with a given budget (see also Sect. 3.5). 


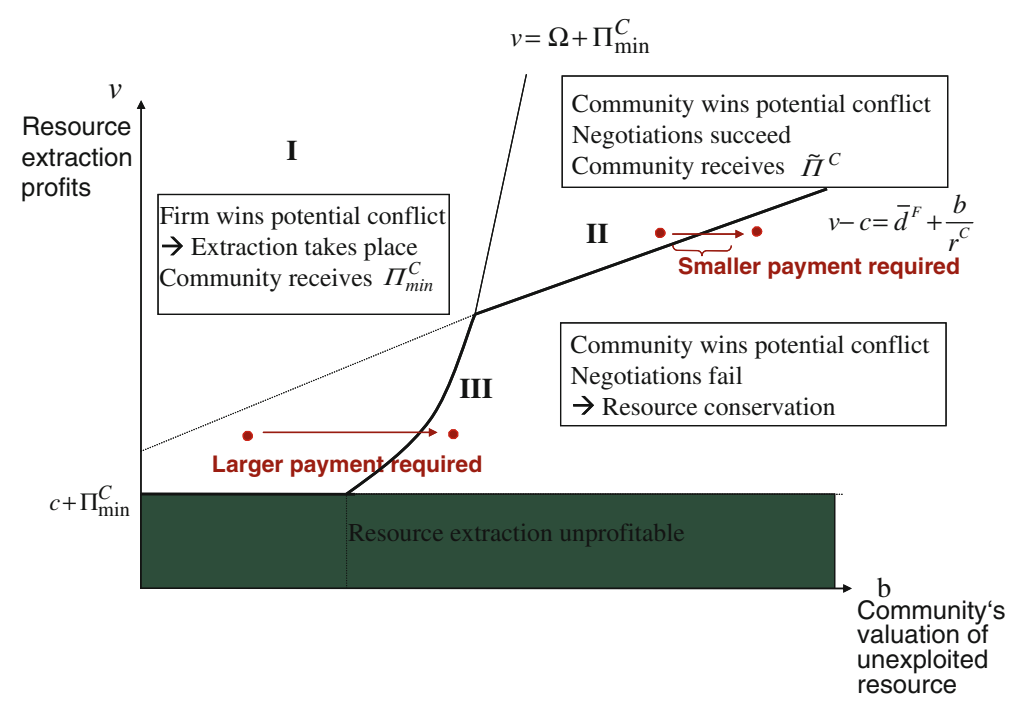

Fig. 5 Trade-off between pro-poor targeting and maximization of environmental benefits

which relatively small payments can induce the desired conservation outcome. In Fig. 2, inclusion in an incentive payment scheme will shift the location of a particular community to the right by the amount of the periodic payment made because it raises the community's per-period valuation of the unexploited resource $(b)$ by this amount.

As discussed previously, to be environmentally effective the payment has to induce a shift from region I or II into region III. Such a shift could be achieved at low cost for communities close to, but to the left of the thick line in Fig. 5. Note that the location of this line depends on model parameters. In particular, an increase in the community's discount rate shifts the thick line to the right. To see this, first recall that $\Omega$ is decreasing in $r^{C}$ (communities with higher discount rates are less likely to win a potential conflict with the firm). Second, negotiation failure is also less likely for higher values of $r^{C}$. Thus, for given values of $b$ and $v$, a community is less likely to be located close to the thick line in Fig. 2 where discount rates are higher. Our model therefore implies an important tradeoff between targeting the poorest communities and achieving the maximum amount of environmental benefits with a given budget.

\subsection{Complementarities Among Policy Approaches}

The results in Sects. 3.1-3.5 highlight the complexities of policy design in a context where decentralization and globalization have led to interactions between local resource-dependent communities and commercial actors interested in resource exploitation. In particular, globalization induces two main difficulties that complicate policy making in a decentralized setting.

First, by raising the extractive value of the resource, globalization may lead to communities joining forces with commercial actors through negotiated resource extraction agreements. Policies aimed at improving environmental outcomes may also impact on the community's reservation utility and thereby its payoffs in negotiations. This may counteract the policy's 
objective by providing an incentive for the community to opt for a resource extraction agreement rather than conservation.

Second, with a lack of effective state enforcement of community resource property rights, communities may be unable to assume de facto ownership over the resource while commercial actors succeed in exploiting resources without community consent. This may result in a situation where a community prefers conservation but cannot enforce it, or one in which a community approves of resources being extracted but cannot join in the benefits since the firm gets away with paying only minimal compensation. Policies aimed at reducing pressure on the resource may unintentionally increase such pressure by undermining the community's ability to self-enforce its property rights, as was seen in the case of providing improved income opportunities outside the resource sector.

Combining different policy approaches can help to improve effectiveness and reduce complexity of policy design. Clearly, with secure property rights the impacts of the other policies are more straightforward. The negative effect of a policy providing improved income opportunities would disappear. The only relevant condition for effective conservation would be the condition for negotiation failure:

$$
v-c \leq \frac{b}{r^{C}}+\bar{d}^{F}
$$

Any incentive payment that raises the value of the unexploited resource high enough to satisfy this condition will be environmentally effective. Note, however, that poorer communities with higher discount rates still require larger payments so that the trade-off between the objectives of maximizing environmental service provision and poverty reduction remains. This implies that a combined strategy of poverty alleviation and incentive payments may be better than relying on payments alone to reach both objectives.

While it appears that providing more secure property rights for local communities is a desirable strategy in any case, it may by itself not succeed in improving environmental outcomes. As discussed in Sect. 3.1, conditions may still be such that communities use their property rights over the resource to make joint extraction agreements with the firm rather than opting for conservation. This happens if condition (6) does not hold. Incentive payments and/or poverty alleviation measures could then be used to induce condition (6) to hold. A policy that does not affect the relevant parameters of this equation, as, e.g., the provision of alternative income opportunities outside the resource sector, will not be environmentally effective in this case.

\section{Conclusions}

Decentralization and globalization have profoundly affected the links between poverty and natural resource management. In this paper, we have argued that globalization implies thatcontrary to common practice in most of the more formal literature on decentralizationcommunities can no longer be considered in isolation. We present a model that incorporates the interaction between local communities and commercial actors interested in intensive resource extraction.

Model results illustrate that globalization complicates decentralization policy exacerbating the weaknesses of current decentralization programmes that have been discussed in the literature, such as weak community property rights and the presence of externalities. With a lack of effective state enforcement of community resource rights, communities may be unable to assume de facto ownership over the resource while commercial actors succeed in 
exploiting resources without community consent. In this sense, globalization may undermine decentralization policy, which tend to be based on the idea of communities developing a sense of ownership over the resource. Rather, the combination of decentralization and globalization may result in a situation where a community prefers conservation but cannot enforce it, or one in which a community approves of resources being extracted but cannot fully join in the benefits since the firm reaps the lion's share. Perhaps unsurprisingly, the poorest communities are most disadvantaged, as high discount rates and low bargaining power prevent them from self-enforcing their property rights and negotiating fair agreements. Even if communities are able to effectively establish control over their resources, globalization may lead to communities joining forces with commercial actors through negotiated resource extraction agreements.

Globalization thus reinforces the need for policies to overcome weaknesses in current decentralization programmes. Our analysis shows that a policy aimed at improving environmental outcomes may affect community payoffs in negotiations with commercial actors, which may counteract the policy's objective. Also, policies aimed at reducing pressure on the resource may unintentionally increase such pressure by undermining the community's ability to self-enforce its property rights as was seen in the case of providing improved income opportunities outside the resource sector. Poverty alleviation can strengthen the community's position vis-á-vis commercial actors, but, if not far-reaching enough may still result in communities selling off resources for short-term economic benefits with few if any environmental improvements.

Incentive payments are a promising approach to overcome this as they translate external values of resource conservation into real financial incentives for local communities. Yet, our results show that designing such schemes effectively is highly complex and implies tradeoffs between targeting the poorest communities and achieving the maximum amount of conservation with a given budget. Providing more secure property rights is a policy that could achieve both environmental improvements and poverty reduction. While the potential of this policy in terms of environmental outcomes remains limited by the presence of externalities, property rights provision and enforcement helps to reduce the complexity in the design of other policies thus implying strong synergies between the policy options. This implies a key role for the state in ensuring that property rights for local resource-dependent communities are clear and secure. A second-best solution would be for third-party organizations such as those implementing incentive payments schemes to help communities in property rights enforcement (e.g. in lowering blockade costs).

Clearly, no single policy option provides a panacea for dealing with the problems of implementing decentralization policy in a context of globalization as defined in this paper. We have demonstrated how a mix of policies combining incentive payments along with the provision of more secure property rights and poverty alleviation has the potential to improve both environmental outcomes and community welfare. With increasing demand for natural resources in both the developed and developing worlds and increasing integration of poorer, rural communities into global markets, there is certainly a need for both more integrated and innovative policy approaches than have been used in the past. To implement these effectively on a case-by-base basis, however, first requires a deeper understanding of how decentralization affects resource-dependent communities exposed to commercial actors wanting access to resources.

Acknowledgments The authors thank Markus Ohndorf, Marcella Veronesi and an anonymous reviewer for useful comments on a previous draft of this paper. The usual disclaimer applies. 


\section{Appendix}

Below we provide further details on the conflict model and the derivation of the boundary condition $v=\Omega+\Pi_{\text {min }}^{C}$, where $\Omega \equiv \frac{c}{r^{F}}\left[\left(\frac{s\left(1-r^{C}\right)}{s-b}\right)^{\frac{\ln \left(1-r^{F}\right)}{\ln \left(1-r^{C}\right)}}-1+r^{F}\right]$. As explained in the text, this condition applies for $s r^{C}<b<s$. A more detailed analysis of game equilibria is provided for a similar setup in Engel and López (2008). A similar derivation was also presented by Burton (2004), which was adopted to the case of community-firm conflict by Engel et al. (2006). The only difference between their conflict model and the one presented here is the minimum payment to the community, $\Pi_{\min }^{C}$, which was assumed zero in Engel et al. (2006). Because this payment is assumed to be obligatory as soon as the firm reaps any profits, we can simply replace profits in the model of Engel et al. (2006) by $v-\Pi_{\min }^{C}$ here.

For $s r^{C}<b<s$, neither party has an incentive to always fight or always withdraw. Rather, the party that could persist in a potential conflict the longest wins the attrition war. Each period the firm stays in conflict it incurs $\operatorname{costs} c$, while its potential gains from fighting are given by the one-time profits from logging unilaterally, $v-\Pi_{\min }^{C}$. The community's cost of staying in conflict in any period is $s$. While in conflict the community gains $b$ each period by preventing the firm from logging. If the community wins the conflict it also obtains $b$ in every period forever. Engel et al. (2006) adapt Burton's (2004) derivation of the maximum lengths of time, $t^{C}$ and $t^{F}$, that the community and the firm can stay in conflict while still receiving a non-negative expected payoff. Setting $t^{C}<(>) t^{F}$, it is shown there that the firm (community) would be able to persist longer in the conflict if $v-\Pi_{\min }^{C}>(<) \frac{c}{1-\rho}\left[\left(\frac{s \varphi}{s-b}\right)^{\frac{\ln \rho}{\ln \varphi}}-\rho\right]$, where $\varphi$ and $\rho$ are discount factors and correspond in our notation here to $\varphi=1-r^{C}$ and $\rho=1-r^{F}$. Thus, defining

$$
\Omega \equiv \frac{c}{r^{F}}\left[\left(\frac{s\left(1-r^{C}\right)}{s-b}\right)^{\frac{\ln \left(1-r^{F}\right)}{\ln \left(1-r^{C}\right)}}-1+r^{F}\right]
$$

we find that the firm would be able to persist in conflict longer if $v>\Omega+\Pi_{\min }^{C}$, and the community would persist in conflict longer if $v<\Omega+\Pi_{\min }^{C}$. Under the assumption of perfect information, the other actor, knowing that the opponent can hold out in conflict longer, would rather withdraw immediately to avoid unnecessary fighting costs. Thus, the line $v=\Omega+\Pi_{\min }^{C}$ represents the boundary condition. For $v$ above this line, the firm is able to obtain de facto property rights to the resource. For $v$ below this line, the community is able to establish de facto rights.

\section{References}

Agrawal A (2001) Common property institutions and sustainable governance of resources. World Dev 29:1649-1672

Agrawal A (2007) Forests, governance, and sustainability: common property theory and its contribution. Int J Commons 1:111-136

Angelsen A, Kaimowitz D (1999) Rethinking the causes of deforestation: lessons from economic models. World Bank Res Obs 14:73-98 
Baland J-M, Platteau JP (1996) Halting degradation of natural resources: is there a role for rural communities? Clarendon Press, Oxford

Binmore K (1985) Bargaining and coalitions. In: Roth A (ed) Game-theoretic models of bargaining. Cambridge University Press, Cambridge

Bluffstone RA (1995) The effect of labour market performance on deforestation in developing countries under open access: an example from rural Nepal. J Env Econ Man 29:42-63

Bose P (1998) Formal-informal sector interaction in rural credit markets. J Dev Econ 56:265-280

Bromley D (ed) (1992) Making the commons work. Institute for Contemporary Studies, San Francisco

Bulow J, Rogoff K (1989) A constant recontracting model of sovereign debt. J Polit Econ 97:155-178

Bulte E, Engel S (2006) Conservation of tropical forests: addressing market failure. In: López R, Toman M (eds) Sustainable development: new options and policies. Oxford University Press, New York

Burton PS (2004) Hugging trees: claiming de facto property rights by blockading resource use. Environ Resource Econ 27(2):135-163

Edmonds EV (2002) Government-initiated community resource management and local resource extraction from Nepal's forests. J Dev Econ 68:89-115

Engel S, López R (2008) Exploiting common resources with capital-intensive technologies: the role of external forces. Environ Dev Econ 13:565-589

Engel S, Palmer C (2008) Payments for environmental services as an alternative to logging under weak property rights: the case of Indonesia. Ecol Econ 65:799-809

Engel S, López R, Palmer C (2006) Community-industry contracting over natural resource use in a context of weak property rights: the case of Indonesia. Environ Res Econ 33:73-98

Engel S, Pagiola S, Wunder S (2008) Designing payments for environmental services in theory and practice: an overview of the issues. Ecol Econ 65:663-674

Ferraro PJ, Uchida T, Conrad JM (2005) Price premiums for eco-friendly commodities: are 'green' markets the best way to protect endangered ecosystems? Environ Res Econ 32:419-438

Gintis H (2000) Game theory evolving. A problem-centered introduction to modeling strategic interaction. Princeton University Press, Princeton

Hook J, Ganguly R (2000) Multinational corporations and ethnic conflict: theory and experience. Natl Ethn Polit 6:48-71

Johnson N, Belsky J, Benavides V et al (2001) Global linkages to community-based ecosystem management in the United States. J Sustain For 12:35-63

Landell-Mills N, Porras I (2002) Silver bullet or fools' gold? A global review of markets for forest environmental services and their impact on the poor. International Institute for Environment and Development (IIED), London

Larson A, Ribot J (2004) Democratic decentralization through a natural resource lens: an introduction. Eur J Dev Res 16:1-25

Larson A, Soto F (2008) Decentralization of natural resource governance regimes. Annu Rev Environ Res 33:213-239

Muthoo A (1999) Bargaining theory with applications. Cambridge University Press, Cambridge

Ostrom E (1990) Governing the commons: the evolution of institutions for collective action. Cambridge University Press, New York

Pagiola S, Bishop J, Landell-Mills N (eds) (2002) Selling forest environmental services: market-based mechanisms for conservation and development. Earthscan, London

Palmer C (2006) The outcomes and their determinants from community-company contracting over forest use in post-decentralization Indonesia. Peter Lang, Frankfurt

Palmer C, Engel S (2007) For better or for worse? Local impacts of the decentralization of Indonesia's forest sector. World Dev 35:2131-2149

Ribot J (2002) Democratic decentralization of natural resources, institutionalizing popular participation. World Resources Institute, Washington

Ribot J, Agrawal A, Larson A (2006) Recentralizing while decentralizing: how national governments reappropriate forest resources. World Dev 34:1864-1886

Richani N (2005) Multinational corporations, rentier capitalism and the war system in Colombia. Lat Am Polit Soc 47:113-143

World Resources Institute (WRI) (2005) World resources 2005: the wealth of poor-managing ecosystems to fight poverty. World Resources Institute, Washington 